\title{
Ciclo Reprodutivo da Carapeba Prateada Diapterus Rhombeus (CUVIER, 1829), no Litoral de PernambuCo - Brasil.
}

\author{
RANILSON DE SOUZA BEZERRA ${ }^{1}$ \\ VERA LÚCIA AlMEIDA VIEIRA ${ }^{2}$ \\ ATHIÊ JORGE GUERRA SANTOS ${ }^{2}$ \\ 1- Pesquisador DCR/CNPq - Departamento de Pesca - UFRPE \\ Email: ransoube@lika.ufpe.br \\ 2-Universidade Federal Rural de Pernambuco Departamento de Pesca.
}

\begin{abstract}
RESUMO
Foram realizados estudos para o conhecimento do ciclo reprodutivo da carapeba prateada Diapterus rhombeus, espécie da família Gerreidae, bastante freqüente nos estuários da costa brasileira e de importância econômica no litoral pernambucano. Os espécimens foram coletados mensalmente em três regiões do litoral de Pernambuco: Itamaracá, Barra de Jangada (Jaboatão dos Guararapes) e Porto de Galinhas (Ipojuca), sendo agrupados trimestralmente. As gônadas foram coletadas, pesadas, analisadas macroscopicamente quanto a sua morfologia externa. Para a análise histológica utilizou-se o método de inclusão na parafina. Também foram calculados os parâmetros reprodutivos tais como: Índice Gonadosomático (IGS), Fator de Condição (K), Comprimento médio da primeira maturação $\left(\mathrm{L}_{50}\right)$, proporção sexual e curvas de diâmetro dos ovócitos e maturação. Os resultados demonstraram que: o IGS representou bem a atividade reprodutiva; o comprimento de primeira maturação $\left(L_{50}\right)$ é de $152 \mathrm{~mm}$; esta espécie possui desova parcelada com dois picos de desova no segundo semestre do ano.
\end{abstract}

\author{
AbSTRACT \\ Reproductive Cycle of The Mojarra Diapterus Rhombeus (Cuvier, 1829), in the Coast \\ Pernambuco State, Brazil.
}

Studies were carried out on the reproductive cycle of mojarra Diapterus rhombeus, a Gerreidae fish species abundant in stuaries of the Pernambuco and Brazilian coast. The specimens were collected monthly in three regions from the Pernambuco coast: Itamaracá, Barra de Jangada (Jaboatão dos Guararapes) and Porto de Galinhas (Ipojuca). The gonads were collected, weighted and morphological macroscopic aspects analysed before processing with traditional histological methods. Reproductive parameters were calculated including: Gonadosomatic Index (GSI), Condition Factor $(\mathrm{K})$, Medial length of first maturation $\left(\mathrm{L}_{50}\right)$, sexual proportion, ovocites diameters curves and maturation curve. The results showed that: the gonadosomatic index (GSI) represented the reproductive activity, the length of first maturation $\left(\mathrm{L}_{50}\right)$ was $152 \mathrm{~mm}$, and this specie is a multiple spawner, with two spawning periods in the second half of the year.

Tropical Oceanography, Recife, v. 29, n. 1, p. 67-78, 2001. 


\section{INTRODUÇÃO}

No Brasil a pesca predatória assim como as freqüentes agressões ao ambiente e modificações estruturais, vem nas últimas décadas transformando os ecossistemas aquáticos, inviabilizando o ciclo reprodutivo de várias espécies aquáticas, sobretudo as diádromas e reofílicas, contribuindo assim para uma constante e acentuada diminuição nos estoques pesqueiros naturais.

Os Gerreideos, entre outras famílias, apresentam relativa expressão na pesca artesanal local, sendo citada por Silva \& Silva (1983), como de acentuada importância econômica para os pescadores artesanais das regiões lacunares do estado de Alagoas. São também colocados como: "maior expressão comercial" na pesca da lagoa Mundaú-AL (Pereira-Barros, 1981).

Dentre os representantes da família Gerreidae a carapeba prateada D. rhombeus, bem como a listrada Eugerres brasilianus, apresentam uma elevada freqüência no litoral nordestino, tendo uma boa representabilidade na pesca artesanal local. São ainda consideradas entre as quatro espécies ícticas mais abundantes no rio Sergipe-SE (Alcantara, 1984).

A carapeba prateada $D$. rhombeus possui uma sistemática bastante definida e já foi alvo de estudos de diversos pesquisadores, como: Ribeiro, 1915; Shultz, 1949; Cervigon, 1967; Pwerry II \& Perry, 1974; Andreata, 1979; Vasconcelos Filho, 1980; Vasconcelos Filho et al. 1981; Leon et al. 1982; Suzuki, 1983; Beltrão, 1988, definindo-o como um peixe marinho costeiro estuarino, relativamente pequeno, habitando próximo ao fundo onde desovam e procuram alimento. Entretanto, dados sobre o ciclo reprodutivo desta espécie ainda são escassos em regiões tropicais.

Apesar da grande importância que os peixes Gerreideos desempenham na região nordestina, pouco se conhece sobre sua biologia (Vasconcelos filho et al., !981). Para que se possa desenvolver uma tecnologia específica, tanto no que se refere à reprodução artificial, quanto à criação de larvas e alevinos, é fundamental obter o conhecimento pleno da biologia de cada organismo (Nobre de Souza, 1988), o que se aplica à espécie em estudo.

Silva \& Silva (1983) registram o a redução nos estoques de outro Gerreidae (Eugerres brasilianus), anteriormente capturado em quantidades expressivas no litoral de Alagoas e citam a necessidade do conhecimento do ciclo reprodutivo das espécies dessa família. Desta forma, pode-se otimizar de uma maneira mais racional a captura dessa espécie, evitando a captura de exemplares jovens ou no período reprodutivo.

Face a boa aceitação da carapeba prateada $D$. rhombeus no mercado, a incontestável redução nos estoques de espécies diádromas, e no grande potencial que os Gerreídeos apresentam para projetos de cultivo e propagação, além de possíveis repovoamentos de ecossistemas aquáticos naturais, onde estas ocorrem naturalmente, o presente trabalho objetivou investigar o ciclo reprodutivo da espécie citada a qual é capturada ao longo do litoral pernambucano. Os resultados aqui apresentados servirão de subsídios para futuros trabalhos de reprodução artificial, bem como para melhor dimensionar e adaptar a pesca artesanal ao ciclo reprodutivo desta espécie.

\section{MATERial e Métodos}

Durante o período de agosto de 1991 a fevereiro de 1993, foram coletados 37 espécimens de $D$. rhombeus, em coletas mensais ao longo do litoral pernambucano, nas praias de Itamaracá, Barra de Jangada (Jaboatão dos Guararapes) e Porto de Galinhas (Ipojuca); oriundos da pesca artesanal local, que para estes fins utilizou os diversos apetrechos desta atividade como: linha de mão, rede de espera, arrasto, molinetes, covos, entre outros. Sendo também aproveitados 6 exemplares oriundos de Itamaracá, coletados entre o período de agosto de 1990 e agosto de 1991, perfazendo um total de 43 espécimes

Tropical Oceanography, Recife, v. 29, n. 1, p. 67-78, 2001. 
Os peixes foram levados ao Laboratório de Fisiologia e Ecologia de Peixes do Departamento de Pesca da UFRPE, onde foram analisados e coletados os dados morfométricos: comprimento total e padrão $(\mathrm{mm})$; peso total e gonadal $(\mathrm{g})$. As gônadas foram retiradas através de abertura abaixo da linha lateral. Logo após, estas foram analisadas morfologicamente quanto a sua turgidez, tamanho, forma, área ocupada na cavidade celômica, coloração, vascularização e visualização de óvulos, sendo então pesadas e fixadas em Bouin Acético. Ao fim destas operações, os exemplares foram agrupados em trimestres e cadastrado em fichas sendo arquivadas no Laboratório.

A partir dos dados obtidos, calcularam-se outros parâmetros reprodutivos: índice gonadossomático (IGS), que representa uma relação entre o peso da gônada (PG) e o peso do corpo (PC), que representa o peso total subtraíndo o peso da gônada (IGS=PG/PCx100). Foram calculados para machos, fêmeas e sexos grupados, os seguintes IGSs: IGS $_{\text {médio, }}$ (média aritmética simples

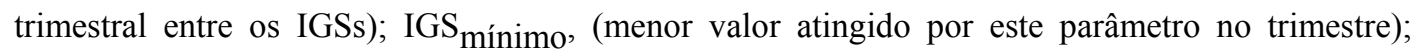

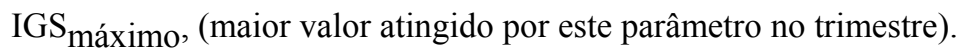

$\mathrm{O}$ fator de condição $(\mathrm{K})$ definido como a relação de ordem decimal, entre o peso total em $\mathrm{g}$ (PT) e o comprimento total do corpo em $\mathrm{mm}(\mathrm{CT})$ elevado ao expoente $3\left(\mathrm{~K}=\mathrm{PT} / \mathrm{CT}^{3}\right)$. Calculou-se os Ks: $\mathrm{K}_{\text {médio }}, \mathrm{K}_{\text {mínimo }}$ e $\mathrm{K}_{\text {máximo }}$ para machos, fêmeas e sexos grupados.

Após a fixação, as gônadas foram conservadas em solução de etanol a $70 \%$ e então aplicados os procedimentos histológicos de rotina (imersão na parafina), para confecções das lâminas para análises em microscopia óptica, as amostras foram coradas com Hematoxilina-Eosina e tricrômico de Mallory.

Com a análise das lâminas foi possível diferenciar de uma maneira mais precisa os estádios maturacionais dos oócitos, servindo de base para a formulação da curva de maturidade e do comprimento médio da primeira maturação $\left(\mathrm{L}_{50}\right)$ (Vazzoler, 1996). Para a determinação do diâmetro dos ovócitos utilizou-se a classificação de Deniel (1981).

\section{Resultados}

Nas amostras ocorreram exemplares agrupados em classes de 100 a $400 \mathrm{~mm}$, sendo o menor exemplar com comprimento total de $102 \mathrm{~mm}$, enquanto que o maior com $354 \mathrm{~mm}$ (Figura 1).

Do ponto de vista macroscópico as gônadas apresentaram características compatíveis com as descritas por Vazzoler (1996). Para o estádio A; faixa delgada e filiforme; estádio B; ocupando cerca de 1/3 a 2/3 da cavidade abdominal, vascularização mais visível; estádio C; coloração róseo alaranjada, bastante irrigada, aspecto entumecido, ocupando quase que totalmente a cavidade abdominal; estádio D; consistência flácida, presença de atresia, ocupando menos de 1/3 da cavidade abdominal.

A observação ao microscópio das lâminas de exemplares imaturos de D. rhombeus revelou a presença de ovogônias, ovócitos I e ovócitos II (Figura 2A). Enquanto que nos testículos a predominância de espermatogônias e espermatócitos primários.

$\mathrm{Na}$ fase de maturação, os ovários apresentaram maior ocorrência de ovócitos III e IV. Para os testículos espermatócitos secundários e espermátides.

Nos ovários maduros, verificou-se a predominância de ovócitos IV e maior irrigação (Figuras 2B e 2C). Enquanto que nos testículos ocorreram espermatócitos primários, secundários, espermátides e espermatozóides (Figuras 2E e 2F).

Os ovários esvaziados apresentaram atresia, folículos rompidos e presença de tecido de cicratização (Figura 2D). Nos testículos observou-se desorganização tecidual, invarginações, luz reduzida e presença de poucos espermatozóides.

Tropical Oceanography, Recife, v. 29, n. 1, p. 67-78, 2001. 
O IGS para sexos grupados variou de 0,22 a 5,28, apresentando seu maior valor no terceiro trimestre, permanecendo alto ao longo do segundo semestre. O IGS para as fêmeas variou de 0,32 a 5,28, apresentando seu maior valor no terceiro trimestre. Para os machos, variou de 0,51 a 4,16, apresentando seu maior valor também no terceiro trimestre (Tabela 1).

$\mathrm{O} \mathrm{K}$ (fator de condição) para sexos grupados variou de $0.009668 \times 10^{-3}$ a $0.019725 \times 10^{-3}$ tendo seu maior valor no quarto trimestre, onde também houve maior variação. Para as fêmeas a variação foi de $0.012396 \times 10^{-3}$ a $0.18933 \times 10^{-3}$ com valores máximos no terceiro trimestre, e sua maior variação no segundo trimestre. A variação do $\mathrm{K}$ para os machos foi de $0.009668 \times 10^{-3} \mathrm{a}$ $0.014801 \times 10^{-3}$ atingindo seu maior valor no quarto trimestre onde também ocorreu sua maior variação (Tabela 2).

Através da análise da curva de maturidade foi possível calcular o comprimento médio de primeira maturação $\left(\mathrm{L}_{50}\right)$ que ficou em torno de $152 \mathrm{~mm}$, enquanto que o $\mathrm{L}_{100}$ foi cerca de $200 \mathrm{~mm}$ (Figura 3).

Foi possível a determinação dos estádios de maturação e do tipo de desova através do diâmetro de ovócitos. Os óvulos apresentaram diâmetros entre 40 e $400 \mu \mathrm{m}$ divididos em três tipos: ovócitos de reserva medindo entre 40 e $120 \mu \mathrm{m}$, os em maturação entre 160 e $280 \mu \mathrm{m}$ e os maturos entre 280 e $400 \mu \mathrm{m}$. As curvas apresentaram dois picos seguidos, um mais intenso que o outro, além do que poderíamos chamar de pico de reserva que representa os ovócitos imaturos. Pode-se diferenciar bem os quatro estádios, como apresentado na Figura 4. Vale destacar que os estádios B e $\mathrm{C}$ foram diferenciados através das Figuras 4B e 4C, que apresentam maiores incidências de ovócitos de reserva e maturos, respectivamente.

A curva de freqüência relativa dos estádios mostrou a ocorrência durante todo o ano de exemplares no estádio A. Estádio B no segundo, terceiro e quarto trimestres. Estádio C no terceiro e quarto trimestres. Estádio D no terceiro e quarto trimestres. O pico do estádio $\mathrm{C}$ foi no terceiro trimestre (Figura 5).

A proporção sexual (fêmea/macho) durante todo o ano foi de 1,55:1. No segundo trimestre foi de $1: 1$. terceiro trimestre $1,29: 1$. No quarto trimestre $2: 1$.

Tabela 1 - Variação trimestral do índice gonadossomático (IGS) para $D$. rhombeus.

\begin{tabular}{|c|c|c|c|c|c|c|c|c|c|}
\hline \multirow[t]{2}{*}{ Trim $\backslash$ IGS } & \multicolumn{3}{|c|}{ IGS $_{\min }$} & \multicolumn{3}{|c|}{$\mathbf{I G S}_{\mathrm{med}}$} & \multicolumn{3}{|c|}{$\mathbf{I G S}_{\max }$} \\
\hline & $\hat{0}$ & q & ठ \& $q$ & $\hat{\sigma}$ & q & đ\& $\&$ & $\sigma^{1}$ & q & $\widehat{\delta} \&$ q \\
\hline JFM* & - & - & 0,35 & - & - & 0,51 & - & - & 0,63 \\
\hline AMJ & 0,51 & 0,32 & 0,22 & 0,55 & 1,54 & 0,69 & 0,59 & 2,75 & 2,75 \\
\hline JAS & 0,47 & 0,66 & 0,47 & 1,62 & 2,30 & 1,83 & 4,16 & 5,28 & 5,28 \\
\hline OND & 1,27 & 0,38 & 0,38 & 1,72 & 1,57 & 1,62 & 2,56 & 2,51 & 2,89 \\
\hline
\end{tabular}

* Nesta amostra todos os indivíduos se encontravam no estádio imaturo, não sendo possível distinguir os sexos

Tabela 2 - Variação trimestral $\left(\times 10^{-3}\right)$ do fator de condição $(\mathrm{K})$ para D. rhombeus

\begin{tabular}{|c|c|c|c|c|c|c|c|}
\hline Trim $\backslash K$ & $\mathrm{~K}_{\min }$ & & & $\mathrm{K}_{\text {med }}$ & & $\mathrm{K}_{\max }$ & \\
\hline & $\hat{0}$ & q & $\widehat{\delta} \&$ ㅇ & $\hat{\sigma}$ & $\hat{\sigma} \&$ \& & $\sigma^{\lambda}$ & $\hat{\sigma} \& \phi$ \\
\hline
\end{tabular}

Tropical Oceanography, Recife, v. 29, n. 1, p. 67-78, 2001. 


\begin{tabular}{llllllllll} 
JFM* & - & - & 0.0102 & - & - & 0.0129 & - & - & 0.0156 \\
AMJ & 0.0123 & 0.0124 & 0.0111 & 0.0126 & 0.0153 & 0.0141 & 0.0130 & 0.0181 & 0.0125 \\
JAS & 0.0132 & 0.0136 & 0.0132 & 0.0140 & 0.0160 & 0.0152 & 0.0147 & 0.0189 & 0.0189 \\
OND & 0.0097 & 0.0128 & 0.0097 & 0.0122 & 0.0146 & 0.0150 & 0.0197 & 0.0165 & 0.0197 \\
\hline
\end{tabular}

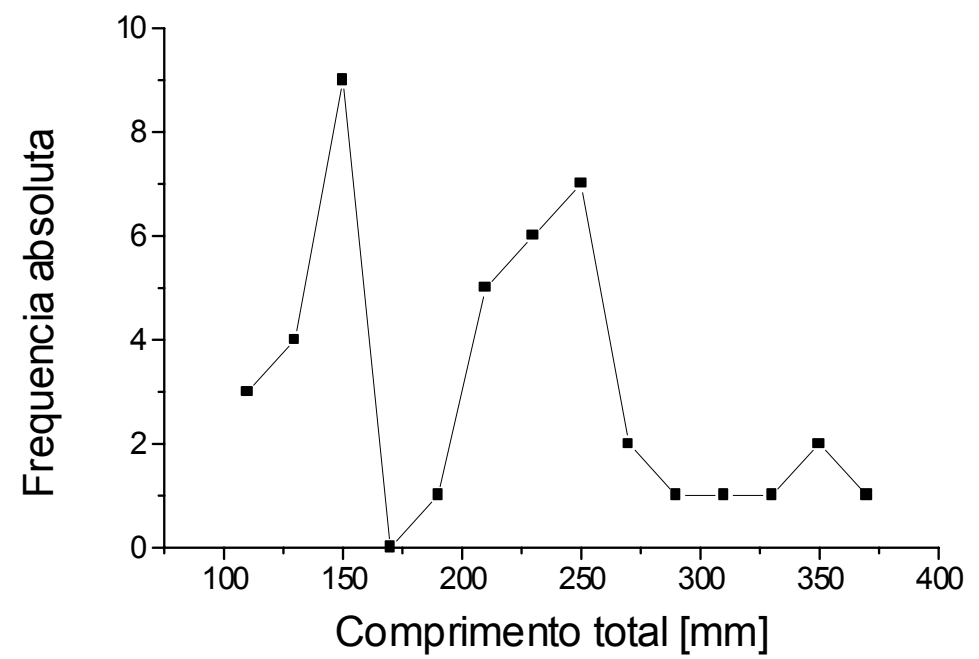

* Nesta amostra todos os indivíduos se encontravam no estádio imaturo, não sendo possível distinguir os sexos

Figura 1 - Freqüência absoluta de exemplares de D. rhombeus, em classes de comprimento total $(20 \mathrm{~mm})$.

Tropical Oceanography, Recife, v. 29, n. 1, p. 67-78, 2001. 

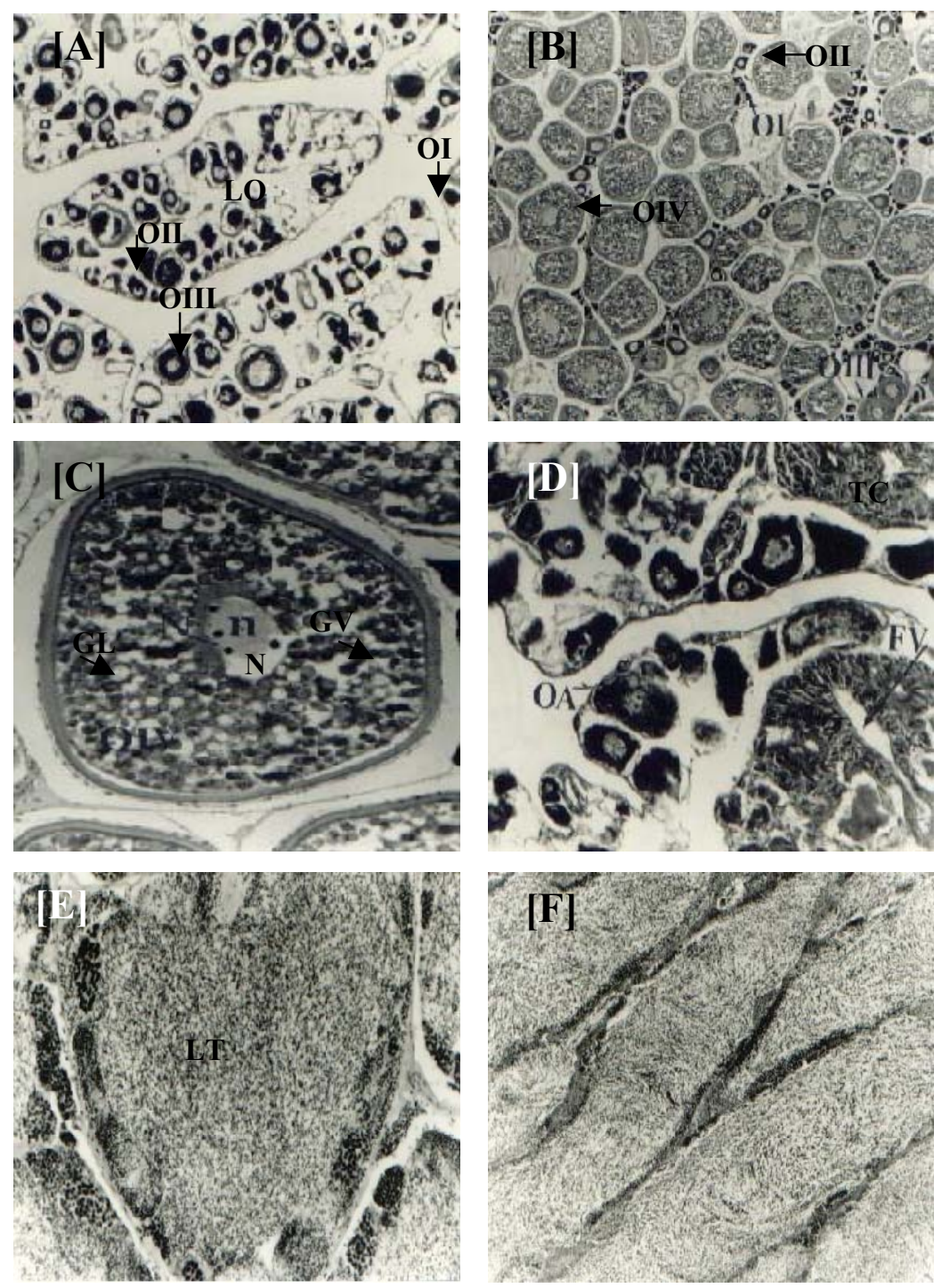

Figura 2 - Fotomicrografias de microscopia óptica, para D. rhombeus apresentando: [A] corte transversal em ovário imaturo; [B] corte transversal em ovário maturo; [C] detalhe de um ovócito IV; [D] corte transversal em ovário esvaziado; [D] Corte transversal em testículo maturo; $[\mathrm{F}]$ corte longitudinal em testículo mostrando aspecto lobular da gônada. Legendas: LO lamela ovariana, OI ovócitos na fase I, OII ovócitos na fase II e OIII ovócitos na fase III, OIV ovócitos na fase IV, GV grânulos de vitelo e GL gotículas de lipídeos, $\mathrm{N}$ núcleo centralizado com $\mathrm{n}$ nucleolos na periferia do envoltório nuclear, OA ovócitos atrésicos, FV folículos vazios e TC tecidos de cicratização, LT luz do túbulo seminífero.

Tropical Oceanography, Recife, v. 29, n. 1, p. 67-78, 2001. 


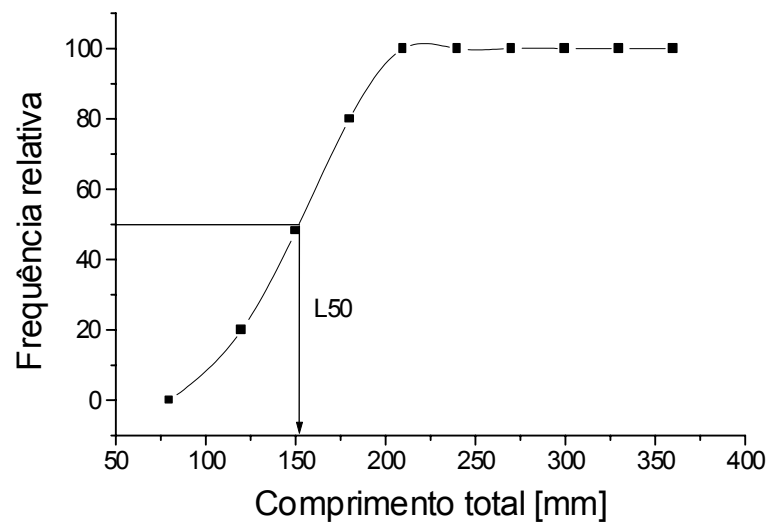

Figura 3 - Distribuição da freqüência relativa por classes de comprimento total, para a população de $D$. rhobeus estudada. $30 \mathrm{~mm}$ de amplitude.
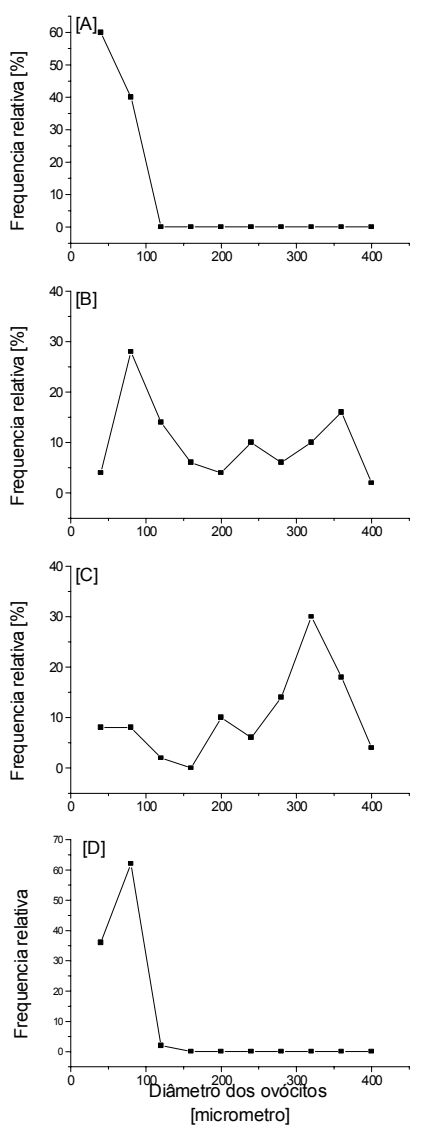

Figura 4 - Distribuição da freqüência relativa do diâmetro dos ovócitos em gônodas de D. rhombeus. Estádio A [A], estádio B [B], estádio C [C] e estádio D [D].

Tropical Oceanography, Recife, v. 29, n. 1, p. 67-78, 2001. 


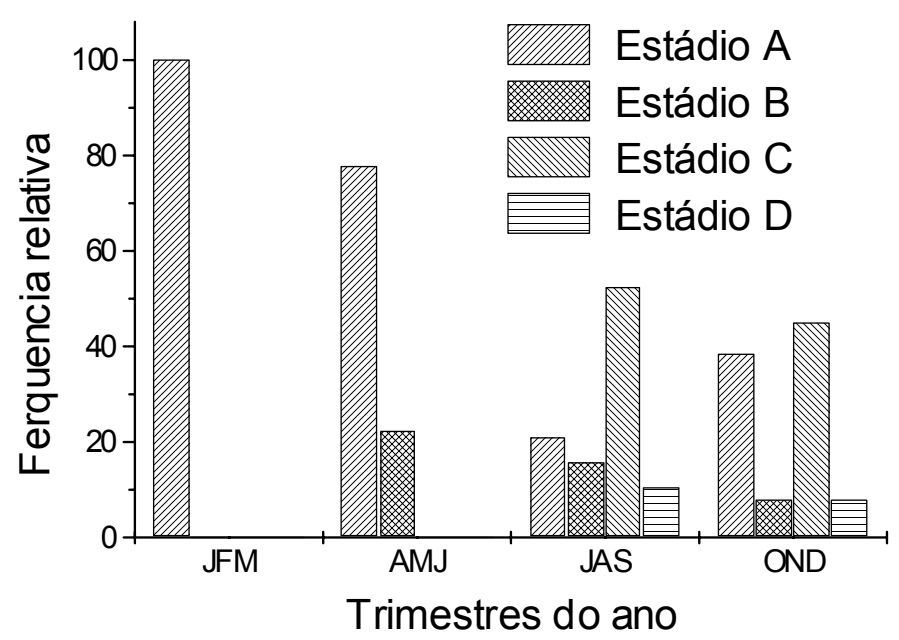

Figura 5 - Distribuição de freqüências trimestral (\%) dos quatro estádios para sexos grupados de $D$. rhombeus.

\section{DiscusSão}

Segundo Vazzoler (1996) a determinação do IGS desempenha um papel muito importante em estudos de reprodução, pois relaciona o peso da gônada com o do corpo, representando, de forma percentual, o desenvolvimento tridimensional da mesma. Ao associar este parâmetro com outros parâmetros mensuráveis, como por exemplo o fator de condição K, podemos, para algumas espécies, considerar a curva como representativa, constituindo-se em um elemento que, associado a outras evidencias, fornece indicações sobre a(s) época(s) de reprodução.

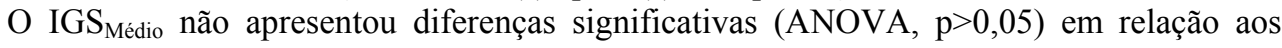
trimestres estudados para $D$. rhombeus. Para sexos grupados no primeiro trimestre os valores desse parâmetro apresentou a menor amplitude $(0,28)$, isto ocorreu pois todos os exemplares capturados eram imaturos. Entretanto, no segundo semestre, com a maior ocorrência de espécimes maturos, houve um incremento na média $(1,83$ e 1,62). Para os machos e fêmeas os maiores valores de IGS foram detectados nos terceiro e quarto trimestres. Estes fatos sinalizam que o segundo semestre é o mais relevante para o período reprodutivo dessa espécie.

O fator de condição, como parâmetro reprodutivo, representa uma relação entre o metabolismo reprodutivo e o desenvolvimento corporal de uma espécie (Vazzoler, 1996). Teoricamente quando em uma população sua variação chegar a zero, esta estará em total equilíbrio. Como isto provavelmente nunca acontecerá, vale a relação de que quanto menor a variação do $\mathrm{K}$ maior o bem estar interativo entre os espécimens de uma população. Levando em consideração este ponto de vista, qualquer alteração de hábito e/ou habitat pode refletir variações neste parâmetro, como por exemplo, uma migração, perdas metabólicas para formação das gônadas, mudanças estruturais e/ou físico-químicas no ecossistema, entre outras, representando assim, se sua análise for periódica e associada a outros parâmetros, um tipo de "índice de bem estar" podendo nos levar ao conhecimento do ciclo reprodutivo.

O fator de condição tem várias aplicações no estudo da biologia de uma espécie (Hile, 1936). Este índice pode indicar a época de desova aproximada, avaliar o estado real de nutrição do peixe, e calcular o peso teórico dos indivíduos. O estado fisiológico de um peixe é condicionado pela interação de fatores bióticos e abióticos. Variações nesse estado podem ser expressas através do

Tropical Oceanography, Recife, v. 29, n. 1, p. 67-78, 2001. 
fator de condição; este indica condições alimentares recentes e varia durante o ciclo de maturidade sexual de um peixe (Angelescu, 1958; Almeida,1966; Vazzoler, 1996).

Também não houve diferenças significativas (ANOVA, $p>0,05$ ) entre os valores médios do fator de condição para sexos grupados, entretanto, maiores variações foram detectadas no segundo semestre, coincidentemente com os maiores valores de IGS. Esta variação ficou mais visualizada nos machos do que nas fêmeas que apresentaram maiores variações no segundo e terceiro trimestres.

Por outro lado, o índice somático, fator de condição e análises morfológicas tem sido utilizados para definir atividades reprodutivas em diversos teleósteos estuarinos: Bairdiella ronchus (Chaves, 1995) Citharichthys arenaceus e C. spilopterus (Chaves \& Vendel, 1997a); Stellifer rastrifer (Chaves \& Vendel, 1997b). Estes parâmetros aliados a análises histológicas das gônodas representam uma ótima ferramenta para o conhecimento da biologia reprodutivas de peixes, sobretudo aquelas cujo esforço de pesca são mais intensos.

A análise histológica das gônadas de D. rhombeus, tanto para machos como para fêmeas, revelou-se, de certa forma, semelhante as características descritas por Vazzoler (1996), não sendo detectada o processo de hidratação pré ovulatória (HPO), observada por Chaves (1995) para o Scianideo B. ronchus.

$\mathrm{O}$ comprimento médio da primeira maturação $\left(\mathrm{L}_{50}\right)$ pode representar, para indivíduos de uma mesma população, o inicio da primeira maturação sexual através do comprimento médio dos indivíduos da população estudada (Vazzoler, 1996). Desta forma, a captura de exemplares menores do que $152 \mathrm{~mm}$ para $D$. rhombeus não é aconselhável, pois levará a quebra do elo reprodutivo, fato que contribuirá para o diminuição nos estoques dessa espécie, o que já está ocorrendo com alguns Gerreideos no Nordeste do Brasil (Silva \& Silva, 1983).

A mensuração do diâmetro dos ovócitos de um ovário de peixes, auxilia gerando evidências sobre o tipo de desova, fornecendo, quando analisado junto com a variação periódica de outros parâmetros, principalmente o IGS, uma confirmação e maior precisão aos dados (Vazzoler, 1996). Com a análise das curvas de diâmetro dos ovócitos para $D$. rhombeus, observou-se que esta espécie possui dois picos seguidos de desova.

A curva de freqüência relativa dos estádios, distribui periodicamente a abundância relativa de cada estádio. Em comparação com o IGS, a variação deste deve ser diretamente proporcional a freqüência dos exemplares maturos, para que se comprove a curva do IGS, como representativa dos picos de desova (Vazzoler, 1996). Este fato ocorreu para a espécie em estudo, o que reforça a eficiência do IGS, como parâmetro indicador de atividade reprodutiva nessa região estudada.

Entre outros fatores que poderiam influir na razão sexual, o suprimento alimentar foi considerado por Nikolsky (1963) como fator importante, ocasionando uma maior percentagem de machos nos rios pobres em alimentos. Estas pesquisas revelam que tanto as taxas de nascimento e de mortalidade, como a disponibilidade de alimento e comportamento reprodutivo, podem influenciar na variabilidade da proporção dos sexos. $\mathrm{O}$ fato da ocorrência maior de fêmeas ao longo desse estudo, exceto durante o segundo trimestre, quando ocorreu uma proporção de 1:1, pode constituir uma evidência de que a população está em equilíbrio com o ambiente, tanto do ponto de vista reprodutivo, como alimentar.

Ao estudar Gerreideos na lagoa Términos das Ilhas de Carmen, ao Sul do México, Leon et al. (1986) relacionou o ciclo reprodutivo das espécies com a pluviosidade. D. rhombeus, durante a época de chuva, foi calculada uma proporção sexual Macho/Fêmea de 1,4:1, freqüência de exemplares juvenis (fase I), medindo entre 40 e $85 \mathrm{~mm}$, e poucos exemplares adultos (Fase III), a partir de $120 \mathrm{~mm}$ de CT. Durante a seca, proporção sexual de 1:1,3 e espécimens juvenis (fase I e II), medindo entre 50 e $114 \mathrm{~mm}$. Para D. auratus foi registrado uma proporção sexual de 1,6:1 durante todo o experimento. Este estudo realizado no México, mostrou uma relação entre o ciclo reprodutivo e a pluviosidade, também observada no nosso experimento, uma vez que historicamente no estado de Pernambuco o primeiro e o segundo trimestres do ano apresentam um maior índice de pluviosidade do que o terceiro e o quarto. Sendo assim, a espécie em estudo apresentou atividade

Tropical Oceanography, Recife, v. 29, n. 1, p. 67-78, 2001. 
reprodutiva no período que geralmente ocorre menor pluviosidade. No entanto, este fato deve ser melhor avaliado posteriormente.

Com os dados coletados ao longo deste estudo foi possível entender melhor o ciclo reprodutivo da carapeba prateada D. rhombeus. As curvas e parâmetros descritos por Vazzoler (1996) demonstraram ser eficientes, fato que contribuiu para se elucidar alguns questionamentos sobre a atividade reprodutiva desta espécie. Assim, conhecimentos foram gerados sobre a biologia reprodutiva de D. rhombeus, sendo de interesse tanto para o dimensionamento racional da pesca, como para a aplicação de técnicas de desova artificial, contribuindo assim para o desenvolvimento do cultivo de D. rhombeus, espécie nativa com ótimo potencial para a Aquicultura.

\section{CONCLuSões}

Com o desenvolvimento desta pesquisa chegamos as seguintes conclusões: a variação do IGS pode ser, nesta região, utilizada como indicação para a(s) época(s) de desova; $50 \%$ da população de $D$. rhombeus, nesta região encontra-se adulta com cerca de $152 \mathrm{~mm}$ de comprimento total $\left(\mathrm{L}_{50}\right)$, sendo assim, este limite tem de ser respeitado para que o ciclo reprodutivo desta espécie seja conservado; nesta área, esta espécie possui dois picos seguidos de desova, que ocorrem no segundo semestre; a interação entre os parâmetros reprodutivos, curvas de maturação e informações adquiridas durante o estudo, sugerem que esta espécie completa o seu ciclo reprodutivo no mar, sua desova ocorre no segundo semestre do ano, com maior pico no terceiro trimestre.

\section{REFERÊNCIAS BIBLIOGRÁFICAS}

ALCANTARA, A. V. Composição da ictiofauna do estuário do rio Sergipe. In: Congresso Brasileiro de Zoologia, 11 Belém. Resumos... Universidade Federal do Pará, 193-194, 1984.

ALMEIDA, N. U. Estudos sobre a maturidade do peixe voador Hindicrthys affinis (Gunther) na costa nordestina do Brasil. Biol. Est. de Pesca, SUDENE, Recife, v. 6, n. 3, 1966, maio-agosto.

ANDREATA, J. V. Osteologia da nadadeira caudal de Diapterus, Ranzani e Eucinostomus Perciformes, Percoidei, Gerreidae. Rev. Bras. de Biol. 39:258-327, 1979.

ANGEleSCU, A. La Merluza del mar Argentino. Serv. Hidrogr. Nav. H. 1958, 1004p.

BELTRÃO, A. C. M. Pisces Gerreidae Gunther (1862) de alguns estuários do estado de Pernambuco, Brasil. Recife, 1988, 120p. Dissertação (Mestrado) - Universidade Federal de Pernambuco, Departamento de Oceanografia.

CERVIGON, F. Los peces in ecologia marina. Caracas: Mongrafia. Fundacion la Salle de Ciências Naturales. 1967, p: 308-355

CHAVES, P. T. C. Atividade reprodutiva de Bairdiela ronchus (Cuvier) (Pisces, Scianidae) na Baía de Guaratuba, Paraná, Brasil. Rev. Bras. Zool. v. 12, n. 4, p 759-766, $1995 .$.

CHAVES, P. T. C.; VENDEL, A. L. Indicadores reprodutivos das espécies de Citharichthys Bleeker (Teleostei, Pleuronectiformes) na Baía de Guaratuba, Paraná, Brasil. Rev. Bras. Zool. v. 14, n. 1, p. 73-79, 1997a.

Tropical Oceanography, Recife, v. 29, n. 1, p. 67-78, 2001. 
CHAVES, P. T. C.; VENDEL, A. L. Reprodução de Stellifer rastrifer (Jordan) (Teleóstei Scianidae) na Baía de Guaratuba, Paraná, Brasil. Rev. Bras. Zool. v. 14, n. 1, p. 81-89, 1997 b.

DENIEL, C. Les poissons plats (Teleoteens, Pleuronectiformes) en Baie de Dovarnenez (Reproduction, croissance et migration des Bothidae, Scorphtalmidae et Soleidae). Université de Bretagne Occidentale. 1981.

HILE, R. Age and growth of the cisco Leucichthys artedi (Lee Sueur), in the Lakes of the northeastern highlands, Wisconsin. Bull. Bur. Fish. Wash., v. 48, p. 211-317, 1936

LEON, A. A.; YANEEZ-ARACIBIA, A.; LINHARES, F. Amezcua. Taxonomia, diversidad, distribuition y abundancia de las mojaras de la laguna de Terminos, Capenche. (Pisces, Gerreidae). An. Inst. Ciênc. del Mar y Limnol. Univ. Auton. México. México, v. 9, n. 1. p, 213-159, 1982.

LEON, A. A.; YANEEZ-ARACIBIA, A.; LINHARES, F. Las Mojarras de la Laguna de Términos: taxonomia, biologia, ecologia y dinámica trófica. (Pisces Gerreidae). An. Inst. Ciênc. del Mar y Limnol. Univ. Auton. México. México, v. 13, n. 1), p. 69-444, 1986.

NIKOLSKY, G. V. The ecology of fishes. London. Academic Press, 1963, 352p.

NOBRE DE SOUZA, R. L. T. B. Aspectos da reprodução do Robalo Centropomus parallelus Poey, 1860 (Pisces Centropomidae) da Região cacaueira do estado da Bahia: um subsidio ao cultivo. Salvador, 1988, Dissertação (Mestrado) - Universidade Federal da Bahia. Salvador.

PEREIRA-BARROS, J. B.Crescimento de Eugerres brasilianus (Piaces Gerreidae) em viveiro. IN: Seminário de Biologia marinha. São Paulo, Academia Brasileira de Ciências, 291-292, 1981.

PERRY II; J. A.; PERRY, S. D. Los peces comunes de la costa atlântica de Costa Rica. Costa Rica, Universidad de Costa Rica, Faculdad de Ciências e Letras, Departamento de Biologia: (Série Ciências Naturales, No 7). 1974.

RIBEIRO, A. M. Fauna brasiliense - peixe (Eleutherobranchios aspirophoros) PHYSOCLISTI. Arquivos do Museu Nacional do Rio de Janeiro, v. 17, p. :3-9, 1915.

SCHULTZ, L. P. Afurther contributiontothe icthiology of Venezuela. Washington, United States Nacional Museum, Smithosinan Institution, v. 99, p. 1-211, 1949.

SILVA, C. S.; SILVA, C. R. S. Comentários sobre a pesca predatória nas Regiões lagunáres de Alagoas. An. Soc. Nor. Zool. 1(1): 119-131, 1983.

SUZUKI, C. R. Guia dos peixes do Litoral brasileiro. Rio de Janeiro, Book's Edições, 1983, $394 \mathrm{p}$.

VASCONCELOS FILHO, A. L. Aspectos gerais sobre a alimentação do carapicu Eucinostomus spp (Pisces Gerreidae), no Canal de Santa Cruz, Pernambuco, Brasil. Rev. Nor. Biol. João Pessoa 3:105-110,.1980

VASCONCELOS FILHO, A. L.; ALVES, M. L. C.; ESKINAZI-LEÇA, E. Estudo ecológico da região de Itamaracá Pernambuco, Brasil. XVIII aspectos gerais sobre alimentação da carapeba

Tropical Oceanography, Recife, v. 29, n. 1, p. 67-78, 2001. 
listrada Eugerres sp. e carapeba prateada, Diapterus sp., (Pisces Gerreidae) no Canal de Santa Cruz. Trab. Ocean. da Univer. Fed. Pernambuco, Recife, v. 16, p. 89-104, 1981.

VAZZOLER, A. E. A. Biologia da reprodução de peixes teleósteos. Maringá-PR: EDUEM: 1996, $169 \mathrm{p}$

Tropical Oceanography, Recife, v. 29, n. 1, p. 67-78, 2001. 